LIBRO

Alfonso de Toro: De las Similitudes y Diferencias.

Honor y Drama de los Siglos XVI y XVII en Italia y España

(Frankfurt a. M.; Madrid: Verhuert/Iberoamericana).

\title{
DE LAS SIMILITUDES Y DIFERENCIAS. HONOR Y DRAMA DE LOS SIGLOS XVI Y XVII EN ITALIA Y ESPAÑA, DE ALFONSO DE TORO
}

\author{
Nicolás Salerno Fernández
}

1

$P_{0}$ al lector medio que se interesa en ahondar en aquellos temas que lo apasionan, sino además a una academia cada vez más reacia a la investigación en profundidad; la acuciosidad no parece ser hoy una virtud, menos aún un requisito, en el ámbito de la crítica. ¿Legado de la hegemonía académica norteamericana o simplemente sino de los nuevos tiempos en que el mantra economicista, “eficacia-eficiencia”, se le impone incluso a la labor del investigador? Las razones de las grandes transformaciones culturales por lo general son múltiples y difíciles de determinar, y lo único que tenemos claro es que hoy, en los albores del siglo XXI, resultaría complicado encontrar en los estantes de una librería algún ejemplar de la raza de Literatura Europea y Edad Media Latina de Ernest Curtius, Mímesis de Eric Auerbach o de Interpretación y Análisis de la Obra Literaria de Wolfgang Kayser, textos que, por varias razones y de diversas formas, seguimos leyendo y citando hasta el día de hoy. Aventuro una hipótesis: lo hacemos pues en ellos

Nicolás Salerno Fernández. Licenciado en Lengua y Literatura Hispánica, Universidad de Chile. Doctor (C) en Literatura, Pontificia Universidad Católica de Chile. Profesor de The Grange School, Santiago.

Estudios Públicos, 110 (otoño 2008). 
encontramos algo que los traslúcidos papers de revistas I.S.I no nos entregan: una visión profunda y clara en sus objetivos —aun cuando puedan pecar de cierta pretensión enciclopedista-, la cual no omite ninguno de los factores involucrados en el proceso de la comunicación literaria.

De las Similitudes y Diferencias: Honor y Drama en los Siglos XVI y XVII en Italia y España (1998), del profesor chileno radicado en Alemania Alfonso de Toro, tiene algo de éstos hitos de la crítica del siglo XX: su largo aliento, pero sobre todo su búsqueda minuciosa y vehemente por develar las razones que logren explicar contundentemente aquello que se propone desentrañar: el problema del honor, en tanto fenómeno socio-éticojurídico-literario-dramático europeo constitutivo de época. Sin embargo, la virtud que más acerca el estudio del catedrático de Leipzig a los textos clásicos de los maestros alemanes de antaño es su capacidad de extrapolar un tema literario, de llevarlo “más allá”, o “más acá” si se quiere, de su “especificidad”. Y no sólo contextualizándolo, sino además contrastando el concepto de honor que subyace a ciertos dramas españoles e italianos de la modernidad temprana (siglos XVI y XVII) con las ideas acerca de este mismo concepto desarrolladas en tratadistas de la época, ya sea del ámbito de la teología, la filosofía moral o de los textos jurídicos, haciéndonos ver de qué modo la literatura, y más específicamente el drama con su potencialidad teatral, tiene la capacidad de crear imaginarios de modo más eficaz que otros discursos portadores del mismo contenido, eficacia que puede percibirse en la permanencia en el tiempo de ciertas ideas generadas a partir de estos textos dramáticos, las que no sólo condicionan al incauto lector/espectador, sino que también son utilizadas por determinados críticos para alimentar supuestos rasgos del “carácter nacional”, como lo apunta el mismo De Toro:

Pero la crítica de la segunda mitad del presente siglo [siglo XX] también se limitó en lo fundamental al análisis de los dramas de Calderón y Lope, y así se creó en la teoría literaria la leyenda del carácter por principio sanguinario de los dramas de honor, y con ello de los españoles, a lo que con frecuencia contribuyó también algún que otro hispanista indeliberadamente. (De Toro: 37)

Si seguimos las ideas del gran teórico del nacionalismo, Benedict Anderson, para quien el origen del concepto tradicional de nación no está en los campos de la ensayística, de la historiografía ni del discurso forense, sino en el literario, podremos dimensionar de mejor forma la relevancia que tiene un estudio acabado sobre el tema y de esta magnitud. A la idea de una 
nación en tanto constructo discursivo, subyace la existencia de un determinado “carácter nacional” para cuya edificación los teóricos/constructores de la nación echarán mano principalmente a la literatura, y sobre todo a aquellos textos y formas literarias que gocen de mayor popularidad y prestigio entre las masas, como el drama. Baste como ejemplo el sabroso dato que entrega Terry Eagleton en su Introducción a la Teoría Literaria, cuando revela que la enseñanza de Chaucer, Shakespeare, Milton, Defoe y otros autores llamados “clásicos” de la literatura inglesa, comenzó recién en el siglo XIX, no en Oxford ni Cambridge, que en esa época todavía despreciaban las literaturas en lenguas vernáculas, sino en las escuelas técnico-profesionales donde se "educaba" a la mano de obra calificada. Tales obras servían para ilustrar un determinado paradigma del “carácter nacional” de los ingleses, ceñido al modelo de comportamiento que la reina Victoria esperaba que tuviesen sus súbditos en las colonias (Eagleton: 41).

En la construcción de la "hispanidad”, o carácter nacional español, el concepto de honor ha jugado un rol central, para cuya edificación se han utilizado como base sobre todo los textos literarios, tales como las crónicas, leyendas, avisos, canciones, proverbios y los llamados “dramas de honor”, de los cuales han bebido los más célebres teóricos de la nación española, como Ortega y Ramiro de Maeztu, cuyo influjo ha sido decisivo no sólo en el desarrollo de la crítica y filología hispánica del siglo XX, sino que también en el ideario del franquismo, en su proyecto de "reconstrucción nacional", el cual dominó el panorama social, político y cultural de España durante gran parte del siglo XX, irradiando su influencia a varios países latinoamericanos $^{1}$.

Al rastrear el origen del concepto de honor en España y contrastarlo con el ideal renacentista italiano de cuño neoaristotélico, De Toro demuestra una particularidad fundamental en la concepción española del honor: que ésta es el resultado de un código militar-feudal-caballeresco usado en la lucha contra los moros durante la edad media, que se reafirma y utiliza en el debate en torno a la pureza de sangre que se lleva a cabo en la península en los siglos XVI y XVII. Esta idea — sin ser original — tiene un alcance que va mucho más allá de lo que De Toro prueba, es decir, que la noción de honor presente en los dramas españoles de los siglos XVI y XVII no tendría su origen en el concepto neoaristotélico presente en los tratados y dramas italianos renacentistas sobre el tema, alcance sobre el cual nos gustaría detenernos.

${ }^{1}$ Dos ejemplos claros de esto son el pensamiento crítico de Menéndez Pidal y Américo Castro. Al respecto es interesante revisar el trabajo de Isabel Jara: De Franco a Pinochet: el Proyecto Cultural Franquista en Chile, 1936-1980, 2007. 
La constante semiotización del honor no es sino una prueba más del rol predominante que éste ha jugado y juega, no sólo en la historia de las ideas, sino en la vida de los sujetos. Con honor se vive, por honor se muere y se mata desde La Ilíada de Homero hasta El Sur de Borges, desde La Orestíada de Esquilo hasta Crónica de una Muerte Anunciada de García Márquez. En Latinoamérica se le ha tematizado por siglos, mostrándolo como un móvil vital, como un concepto en el cual convergen Eros, Tánatos e ideología, ya sea desde una perspectiva crítica o laudatoria. Autores como José Hernández y Ricardo Güiraldes en Argentina, Jorge Inostroza y Olegario Lazo en Chile y la mayoría de los llamados “escritores cívicos” latinoamericanos tematizan el honor en sus obras en tanto rasgo distintivo del carácter nacional, herencia del sustrato cultural hispánico. Si tenemos en cuenta lo dicho por Anderson relativo a la indisoluble ligazón entre el surgimiento del capitalismo impreso ${ }^{2}$, es decir, de la publicación y venta masiva de libros luego de la invención de la imprenta, y la construcción de los imaginarios nacionales, es fácil ver que esta idea del honor, implícita en la construcción discursiva de las identidades colectivas de las naciones hispanoamericanas, proviene más de la ficción que de la tradición jurídica, filosófica o teológica. De Toro muestra, en lo relativo a uno de los ejes centrales en torno a los cuales se articula el concepto de honor, la venganza, que en la tradición jurídica española de los siglos XVI y XVII se hacía todo lo posible para evitar que los conflictos de honor se resolvieran a través de ésta:

La legislación romana pasa a formar parte de los textos legales que se constituyen en Europa desde el siglo X, para ser luego completada por el derecho germánico, la ética antigua, la doctrina cristiana y la teología y filosofía morales. De esta tradición intelectual surge en los siglos XVI y XVII una conciencia jurídica que excluye la venganza y que intenta solucionar todos los conflictos con la aplicación de medidas socialmente fijadas. Sólo en el caso flagrante la ley deja a cargo del marido la muerte de la adúltera o de los adúlteros; pero al mismo tiempo introduce una serie de obstáculos e inconvenientes potenciales cuya finalidad había de ser que aquél desistiera de una acción así (De Toro: 183).

${ }^{2}$ Benedict Anderson se refiere a la industria editorial como: "Una de las primeras empresas capitalistas. La actividad editorial experimentó la busca incesante de mercados. Los primeros editores establecieron sucursales por toda Europa (...) y dado que el período de 1500 a 1550 fue de excepcional prosperidad en Europa, la actividad editorial compartió el auge general. Más que en cualquiera otra época, era una gran industria bajo el control de capitalistas ricos” (Anderson: 64). 
Este proceder jurídico está en directa contradicción con el de los personajes que veían su honor mancillado en los dramas. El profesor de Leipzig muestra cómo la venganza es el eje en torno al cual se articula la representación del honor en el drama, caracterizando a los vengadores como personajes que sufren una profunda esquizofrenia: por un lado quieren ejercer una venganza que represente un escarmiento que sea recordado por el mundo, pero por otro quieren impedir que la venganza sea reconocida como tal, puesto que ésta pone al descubierto la ignominia al mostrar que tiene que haber sido precedida por una deshonra, frente a lo cual De Toro concluye que:

\begin{abstract}
Se plantea así la cuestión del mundo, o la opinión pública, para los que los vengadores desean ejecutar la venganza secreta. Aquí, a nuestro juicio, y como en algunas tragedias de honor italianas, sólo hay una respuesta: la venganza está al servicio de la satisfacción de la vanidad masculina humillada y debe funcionar como advertencia para el receptor. El mundo apelado no es el de los personajes dramáticos, sino el del lector o del espectador. (De Toro: 487)
\end{abstract}

De este modo, la discordancia entre lo considerado correcto en la legislación de la época y lo llevado a cabo por los personajes de los dramas de honor revela la ideología que subyace a estas representaciones literarias, las cuales buscaban caracterizar a España como el último bastión del código caballeresco medieval, cuya matriz de sentido es, sin duda, el concepto de honor, entendido "medievalmente", cubriendo de este modo con un espeso velo la progresiva racionalización de las leyes, códigos de conducta y penas que ocurría en la península fruto del influjo del renacimiento italiano.

Si bien resulta complejo hablar de un "proyecto nacional" en la España del llamado "Siglo de oro”, la necesidad de cohesión social que implicó la coyuntura imperial precipitó el surgimiento de ciertas instituciones "normalizadoras”, como la inquisición, que “velaban” por la pureza de la raza y de la fe, además del patrocinio del poder político a determinadas manifestaciones culturales, tales como la publicación de la primera gramática castellana y el apoyo y difusión de dramaturgos y escritores que ensalzasen en sus obras virtudes como el honor, la pureza de sangre y la superioridad y legitimidad de la monarquía absoluta como forma de gobier$\mathrm{no}^{3}$, manifestaciones que terminaron constituyéndose en numen y fundamento de lo que siglos después serían los proyectos nacionales en España y gran parte de Latinoamérica.

\footnotetext{
${ }^{3}$ Pensamos sobre todo en los dramas de honor y en el teatro de Lope de Vega.
} 
Hemos mencionado que el estudio pretende investigar el problema del "honor" como un fenómeno socio-ético-jurídico-literario-dramático-europeo, constitutivo de época. Según Alfonso de Toro el concepto de honor es una especificación que se deduce de las representaciones generales del honor; el autor acota al respecto: "Una concepción del honor se puede definir como la suma sistemática de conceptos del honor; o bien representa un sistema de relaciones en que los distintos conceptos del honor entran en un determinado orden jerárquico en los planos ético, jurídico y lógico” (De Toro: 23).

Por código de honor se entenderá la estructura de los valores y actitudes ligados a una determinada concepción del honor. De Toro afirma al respecto: "El código de honor es la concretización pragmático-actancial de una determinada concepción del honor” (De Toro: 23).

Tal como habíamos señalado, De Toro especifica que el honor es el resultado de un código militar-feudal-caballeresco del cual se valían los "prohombres" cristianos en su lucha contra los moros en el medioevo, código que se encuentra cifrado en los dramas y tratados ya mencionados, también en las polémicas en torno a la pureza de sangre de los siglos XVI y XVII. Al estudiar este concepto en los dramas y tratados sobre el honor en España e Italia, también se busca desestimar la idea de que el tema del honor haya sido un asunto propio de la cultura hispánica, más aun, se busca probar que éste no era sólo un tema literario, sino cultural, determinante para la época; así, Alfonso de Toro busca, en un pormenorizado estudio, abordar el tema del honor en el marco de un contexto cultural amplio que dé cuenta de su origen y función.

En primera instancia De Toro se propone reconstruir el concepto de honor y el drama de honor en su espacio y establecer así una relación intertextual e intercultural entre ambos. La necesidad tanto de reconstruir el concepto como de llevar a cabo estas relaciones intertextuales e interculturales obedece a lo que él considera un hiato en la crítica existente sobre el problema, tanto en el caso italiano como en el español.

En el caso italiano, De Toro puntualiza que los estudios al respecto han sido realizados desde una perspectiva teórica semántica-inmanentista. Lo que él se propone, por el contrario, es llevar a cabo un análisis epistemológico del problema, a la luz del cual descubre que, a diferencia de lo afirmado por Américo Castro, hay una serie de obras dramáticas del renacimiento italiano que pueden ser caracterizadas como “dramas de honor”, dentro de las cuales se encuentran varias tragedias y comedias. El error que habría 
cometido la italianística habría sido concentrarse en el grado de artisticidad de los dramas por un lado y, por otro, en la clasicidad de los mismos, en desmedro de su contenido, dedicándose primordialmente a estudiar el grado de fidelidad de la tragedia renacentista italiana con los parámetros que Aristóteles estableció para la tragedia clásica. De este modo, los dramas renacentistas italianos, al ser medidos con la vara aristotélica ${ }^{4}$, siempre resultaban desfavorecidos, lo cual mermó la atención de la crítica sobre ellos.

El caso español es distinto, no hay duda respecto del interés que el tema del honor ha concitado en la crítica española. De Toro reconoce un trato sistemático del concepto, siempre ligado a los temas del matrimonio, el adulterio, la venganza y el duelo, que se encuentra documentado desde el siglo XII y en textos de naturaleza muy distinta, lo que hace particularmente difícil el examen en torno a ellos. Textos legislativos, tales como fueros, leyes y ordenamientos, textos de filosofía moral y teología y libros de confesión y sermonarios, entre otros, discurren sobre el honor y sus implicancias. Pese a la abundancia de material al respecto, la hispanística necesitó mucho tiempo para relacionar el tema del honor presente en los dramas con la filosofía moral y la teología. El pionero en este sentido es Américo Castro, quien en su célebre artículo: “Algunas Observaciones acerca del Concepto de Honor en los Siglos XVI y XVII”5 aborda el tema. Sin embargo su error — a juicio De Toro - consiste en sostener que la iglesia había autorizado en el siglo XVII la venganza de honor en casos de adulterio, aseveración que no sólo entra en directa contradicción con las principales proposiciones ético-religiosas en vigor en la época, como el profesor De Toro demostrará posteriormente, sino que es además históricamente falsa. Es en este punto en el que De Toro cree necesario ahondar, con el propósito de deslegitimar la idea de que los dramas de honor han de entenderse como reproducción verídica de la realidad histórico social de la época. Tal idea, denuncia el catedrático de Leipzig: "Se seguirá manteniendo hasta la actualidad por parte de la hispanística. Precisamente la actitud acrítica ante tales afirmaciones, o el descuidar el examen de proposiciones reconocidamente conducentes al error, han contribuido voluntaria o involuntariamente a la leyenda arriba citada del carácter sanguinario y de la obsesión del honor de los españoles (De Toro: 43).

Así, aclaradas las deficiencias que la crítica hasta ese entonces vigente presentaba en torno a la dilucidación del origen y función de los dramas de honor en España e Italia en los siglos XVI y XVII, De Toro

\footnotetext{
${ }^{4}$ Nos referimos a los parámetros que establece Aristóteles en su Poética sobre las características de la tragedia.

${ }^{5}$ Publicado en Revista de Filología Española, 3 (1916) 1-50; 357-385.
} 
enumera los objetivos que se propone lograr en su estudio. Primero, tanto para el caso italiano como para el español, busca:

a) La construcción de un modelo sobre la teoría de los géneros para textos dramáticos con especial atención a los dramas de honor, un modelo específico de análisis e interpretación que resulte capaz de incorporar una gran cantidad de variantes en el plano de los personajes, las acciones, las concepciones del honor y los enunciados textuales.

b) Esbozar un modelo tipológico cultural que describa el saber cultural de los siglos XVI y XVII que entra en juego en los dramas de honor, principalmente en España. Tal modelo deberá dar razón de las relaciones interculturales e intertextuales entre el sistema cultural italiano y el español y los dramas de honor y determinadas disciplinas del saber de cada sistema cultural. En base a los textos compuestos por los autores, el modelo nos mostrará cómo pensaban éstos sobre la realidad de entonces.

c) Parcialmente buscará revelar, en el caso de los dramas de honor italianos, los siguientes puntos: describir las áreas del honor, del matrimonio, del adulterio y de la venganza por causa del mismo en el contexto de la legislación, pero sobre todo de la filosofía del derecho y de la filosofía y teología morales. Demostrar la existencia del drama de honor desde comienzos del siglo XVI organizando un modelo semiótico-estructural que incorpora su especificidad. Todo esto a partir de relaciones intertextuales e interdiscursivas entre las áreas de la filosofía del derecho y la teología moral y los dramas de honor italianos.

d) En el caso español, el autor se propone realizar una descripción de las áreas de honor, matrimonio, adulterio, venganza de honor, limpieza de sangre y campo léxico-semántico del concepto de honor. Lo importante, enfatiza De Toro, no será tanto la aclaración exclusiva de un concepto y su entorno como la fijación de su significado y función en un lugar sintagmático, perfectamente determinado de un cierto discurso, lo que, además, es imprescindible para la clarificación de sus transformaciones.

Creemos que la completísima investigación del profesor De Toro tiene su punto más alto en la reconstrucción del honor y de los dramas de honor en su espacio, a partir de la comparación de un acabado modelo referencial, intercultural e intertextual de los siglos XVI y XVII, mostrando que el eje en torno al cual se articulan estas piezas - la venganza- ha perdido su capacidad de restituir el honor mancillado, en la medida en que forma parte de un sistema de valores caduco. 
En la reconstrucción del “metatexto”, es decir del contexto de producción que se supone estas obras en cuestión modelizan, De Toro se refiere en primer lugar a la experiencia de los adulterios, venganzas de honor y ejecuciones aisladas, que, pese a que generaban gran conmoción en la época, raramente se tenía noticia de ellos; lo que sabemos de ellos proviene de los memoriales, leyendas y avisos, es decir, de lo que De Toro denomina “saber cultural”. En los siglos XVI y XVII se presentaban ciertos comportamientos que el autor identifica como “relajación de las costumbres”, es decir: galanteos públicos, raptos, violaciones y concubinato, los cuales generaban enfrentamientos tales como duelos o aventuras bélicas varias ligadas al problema del honor, que son sindicadas como detonantes de estas reacciones ilícitas. De Toro aclara al respecto: "Los conflictos de honor, y más aún, o sobre todo, los que desembocan en una venganza de honor, son siempre asuntos extraordinarios, que en España se recogen por ejemplo en los memoriales, leyendas y avisos (saber cultural); lo que, por el contrario, cumple la norma, no es un suceso digno de representación. Por tanto, si los adulterios y las venganzas de honor hubieran estado en España a la orden del día, si los españoles hubieran estado tan obsesionados por el honor y la venganza como los representaban los dramas de honor, las unidades del sistema cultural matrimonio, divorcio, venganza de honor y honor apenas habrían sido tratadas como algo singular, o como hecho histórico, no digamos ya literario" (De Toro: 525).

El autor, en su reconstrucción del “metatexto” también caracteriza la situación de moros, judíos y cristianos, en la medida en que resulta extremadamente importante para la reconstrucción del código de honor, ya que el honor era exclusivo de los denominados “cristianos viejos”, es decir, de aquellos individuos "limpios” de sangre, que podían probar la inexistencia de antecedentes judíos o moros en su genealogía. La situación de moros y judíos es vital para lograr una correcta comprensión de la escala social en la España de la modernidad temprana. En el tope de ésta estaban los nobles "limpios de sangre”, quienes jamás pierden su lugar de privilegio en la sociedad. Los campesinos o terratenientes limpios de sangre permanecen sin privilegio. Por otro lado, los judíos conversos son discriminados y, en caso de querer acceder a cargos públicos, su linaje es exhaustivamente investigado con el objeto de fundamentar su exclusión.

De este modo la ideología intrínseca del código de honor gira en torno a los ejes matrimonio-honor-venganza de honor-limpieza de sangre. El adulterio rompe el círculo de honor y la venganza lo restituye, entendiendo siempre la venganza como un hecho aislado y excepcional. La limpieza de sangre juega un rol esencial, en la medida en que el carecer de ella resulta 
una de las principales causas del deshonor. El honor se sitúa por encima de la vida como el bien terrenal más ennoblecedor y la deshonra es percibida como la muerte en vida. De Toro plantea claramente que los conflictos de honor no son "pan de cada día", menos aún la venganza de honor: "La venganza de honor es en la España de los siglos XVI y XVII básicamente un asunto literario" (De Toro: 542).

Su absolutización, ya sea a partir de leyendas, memoriales, avisos y dramas de honor, no es sino un medio para asegurar la persistencia de un sistema monárquico-absolutista-patriarcal y católico, en ningún caso el reflejo de las costumbres de la época: "El drama de honor del siglo XVII es una compleja concretización textual del sistema cultural español de los siglos XVI y XVII. Como texto artístico no es reproducción/reflejo de esa realidad ni del sistema cultural, sino que, con ambos como punto de partida, instala más bien un plano significativo secundario que ha de comprenderse como un modelo interpretativo de las diversas disciplinas del saber del sistema cultural y como propia realidad literaria” (De Toro: 523).

De acuerdo con las leyes y con la filosofía del derecho de la época, la justicia por cuenta propia estaba tajantemente prohibida con una sola excepción: el caso flagrante de adulterio. Las penas que establecía la ley a quienes vulneraran el código de honor eran severísimas e iban desde la pérdida de los bienes, pasando por el destierro y la pena de muerte. Las leyes no eran menos duras para quienes tomaban la justicia por sus manos, dado que éstos podían ser excomulgados de la iglesia en caso de no arrepentirse. Dentro de los dogmas de la iglesia, De Toro estudia la teología moral a partir de dos visiones: el probabilismo y la casuística. La primera prohíbe la justicia por propia mano, tolerando sólo la muerte en arrebato pasional y no con pocas restricciones. En la segunda todos los casos de violencia son condenados, teniéndose mayor tolerancia con unos que con otros. El argumento del laxismo, visión que corresponde a la filosofía moral de la época, también es revisado por De Toro. El laxismo plantea que la lógica casuística genera confusión, puesto que las excepciones podrían convertir en explicables y justificables todos los casos de venganza por cuenta propia, ante lo cual se opta simplemente por condenar el asesinato. Por último están los libros de confesión y los escritos de los predicadores, en los cuales se percibe una visión bastante más indulgente que la de la teología y filosofía moral, proponiéndose penitencias a través de las cuales quien había tomado la justicia por sus manos podía lograr la absolución.

En contraste con lo planteado por las leyes, la filosofía y la teología moral de la época, en los dramas de honor se nos presentan obras donde, ya sean con final feliz, final no-feliz o final infeliz, los personajes son extremadamente susceptibles a todo aspecto relacionado con el tema del honor, 
generándose por este motivo venganzas de honor; paradigmáticos en este sentido resultan los dramas Peribañez y el Comendador de Ocaña y La Venganza Venturosa de Lope de Vega.

De cualquier modo, en los dramas hay una importante desviación respecto a los conductos regulares que se debían seguir para la solución de un conflicto de honor: los personajes masculinos no se dirigen a la justicia ni se la toman por cuenta propia en un acto pasional. Guiados por ciertos indicios, matan siguiendo un plan a los adúlteros supuestos o de hecho. El asesinato de los adúlteros en los dramas de honor no tiene como objeto el escarmiento, los vengadores por lo general encubren el asesinato como accidente para impedir que se conozca la deshonra. Posteriormente, al ser conocida la venganza — siempre en un círculo reducido-, el vengador es alabado y recompensado.

En los dramas de honor la absolutización de este concepto tiene más que ver con la imagen pública del deshonrado, con el "qué dirán”. El honor sigue estando por encima de la vida misma, sin embargo aparece como capaz de disociar el juicio y como una obsesión que puede detonar la misantropía. La venganza aparece como un medio natural, transmitido al marido como un procedimiento válido para solucionar los conflictos de honor.

Morir o matar por honor, aparece en estas piezas como una acción, aunque compleja, común y validada dentro del mundo representado. Al dar una razón para la muerte en estas obras que, ciertamente, fueron más conocidas por los individuos de los siglos XVI y XVII de España e Italia que las leyes o los dogmas de la iglesia, se está transmitiendo a los espectadores de este tipo de piezas teatrales la idea de que existen "razones superiores" que justifican plenamente actos considerados por la sociedad como ilegales, y, aun más, la noción de que ciertos individuos, eventualmente, podrían estar más allá de la ley de los hombres y de Dios.

Alfonso de Toro concluye que estas obras sirven, a través de la absolutización del honor, para legitimar los privilegios de la capa social dominante, la aristocracia, limpiando su imagen pública frente a los flagrantes atropellos a la ley que ésta pudiese cometer en pos de la preservación de sus prerrogativas, recreando un orden deseado, el orden moralmente superior. En una afortunada comparación con El Quijote, De Toro apunta:

Precisamente El Quijote, una obra condicionada en la estructura profunda por fenómenos epistemológicos comparables a los de los dramas de honor, conserva su actualidad por la manera de la representación y, sobre todo, por el objeto representado: la búsqueda y la nostalgia de un sistema cerrado, unitario, que descansa en sí mismo, un sistema que ya no existe. (De Toro: 542) 
Al recalcar la vigencia del clásico de Cervantes se recalca la caducidad de los dramas de honor, de los cuales, según De Toro, ningún mensaje con sentido puede extraerse, salvo contadas excepciones.

A través de los dramas de honor se propugna una moral que ensalza el parecer por sobre el ser, en la medida en que al vengador encubre su venganza, poniendo sobre el escenario virtudes nuevas como la astucia, la sagacidad, la discreción y la insinceridad, mostrando una idea del honor entendido como: "Fama, la opinión del otro, el honor es el bien más grande y más alto, y por ello está sobre la vida; una vida sin honor es igual a la muerte" (De Toro: 535).

De este concepto del honor, presente en los dramas, surge un código que nada tiene que ver con el ideal caballeresco; De Toro enfatiza esto al final de su texto:

El concepto y el código de honor ya no existen en el sentido de entonces, han cedido el sitio al pensar en términos de prestigio, a los símbolos del status quo. Quien hoy en día se remita al honor o a la virtud en el contexto de la infidelidad matrimonial corre peligro de exponerse a la burla y al ridículo, puesto que el honor estaba íntimamente vinculado con el origen noble, y la virtud a una mentalidad profundamente religiosa (De Toro: 543)

Así se confirma, a través de uno de los estudios más completos y documentados sobre un tema fundamental de la primera modernidad, que el honor es un concepto clave en la constitución de la ideología europea, que merece ser trabajado con la detención y el cuidado con que lo hace Alfonso de Toro, y que es capaz de iluminar problemáticas que, aunque van mucho más allá de la especificidad literaria, surgen de ella.

\section{REFERENCIAS BIBLIOGRÁFICAS}

Anderson, Benedict: Comunidades Imaginadas. Fondo de Cultura Económica, 2004.

Castro, Américo: "Algunas Observaciones acerca del Concepto de Honor en los Siglos XVI y XVII”. En Revista de Filología Española, 1916.

Eagleton, Terry: Una Introducción a la Teoría Literaria. Fondo de Cultura Económica, 2001.

Jara, Isabel: De Franco a Pinochet: el Proyecto Cultural Franquista en Chile, 19361980. Colección Teoría, Departamento de Teoría de las Artes, 2007. 